\author{
JULIO ESTRADA
}

\title{
...una nueva forma de respirar
}

L

A CAPACIDAd MUSICAL de Karlheinz Stockhausen (1928-2007) para estructurar, experimentar y proponer caminos lo coloca a la vanguardia del pensamiento de la composición en la segunda mitad del siglo xx y el inicio del xxI, lapso en que se observan, grosso modo, tres periodos divisorios de su obra, el último de los cuales es el más amplio y se distingue por la afición al teatro musical y la devoción por la producción operística:

- Serial (I950-I960)

- Aleatorio (I96I-I968)

- Esotérico (1968-2007)

La obra escrita referida adopta un sendero más bien estrecho y formal, evocador de un laboratorio de ideas, como se observa en la serie de Klavierstücke, donde predominan los códigos fijos y una inclinación por la búsqueda sistemática. Esta obra no modifica de manera sustancial ni sintetiza tampoco la apertura que distingue al autor en la creación electroacústica, radical evolución autónoma que, en paralelo o fundidos entre sí, sostienen Gesang der Jünglinge (1956), Telemusik (1966), Hymnen (1967), Sunday Farewell (200I-2003) y, con inédita alianza entre electroacústica y música instrumental y vocal, Kontakte para piano y electroacústica (I958-1960), Mikrophonie I para tamtam, dos micrófonos, dos filtros y controles (1964), Mikrophonie II para doce cantantes, cuatro moduladores de anillos ${ }^{\mathrm{I}}$ y órgano eléctrico (I965), y Mantra para dos pianos y moduladores de anillos (I970). ${ }^{2}$

I. Aparato que produce la suma y la diferencia de la frecuencia recibida como señal electrónica.

2. De dicha lista excluyo deliberadamente Helikopter Streichquartet (1992-1993), bizarro y ruidoso producto, muy distinto del interés espacial que la misma partitura propone para las cuerdas. 
La electroacústica en Stockhausen es el espacio privilegiado de nuevos métodos e ideas, de innovaciones y riesgos, donde la imaginación y la experiencia crean un territorio casi cinematográfico en que la música se confunde con la realidad y fluye como una atmósfera de éter con una evolución autónoma que incita a la aventura perceptiva. Esa desenvoltura y esmero provienen de la intuición y del oficio que le procura el temprano, también privilegiado contacto con la radio de Colonia — Westdeutscher Rundfunk (WDR) — que deviene el taller de una búsqueda facilitada y apoyada por expertos que dan origen a hallazgos en la especialización. Entre otros, la creación de una esfera giratoria integrada por múltiples bocinas grabadas por micrófonos fijos o, en general, el acceso permanente a artefactos novedosos — moduladores de anillos, micrófonos de contacto, sistemas de filtraje de frecuencias u otros - que le ponen a la delantera de la ejecución en vivo de la música electroacústica.

Faceta privada y de grupo, la música tecnológica de Stockhausen aporta la evidencia del naufragio en el siglo xx de buena parte de instrumentales, sintetizadores o computadoras que cambian velozmente de plataforma de trabajo, de instituciones que surgen con éxito —el laboratorio di Sonologia de Milán y el de la Universidad de Columbia, el centro de la Recherche Musicale de París y el de Music and Acoustics de Stanford, los institutos de Recherche et Coordination Acoustique/Musique, entre otros- y tienden a un futuro borroso cuando pretenden fijar pautas estéticas sin producir obras ni dejar oír a autores cuya calidad creativa legitime la abundancia de recursos y de búsquedas. $\mathrm{Si}$ la demasía estorba el equilibrio entre el tiempo del vértigo - Ilinx - y la estabilidad de la tradición —aquí Mnemósine-, la inspiración stockhauseniana avanza y se mantiene en sintonía con una de las primeras percepciones de la electroacústica, el Poema electrónico de Varèse, muestra de una imaginación magistral para vehicular el nuevo arte sonoro.

El creador germano aporta ideas nuevas y asimila de manera constante contribuciones externas, pero no se permite reconocer una de sus influencias más significativas, Henry Dixon Cowell (1897-1965), cuando teoriza en "wie die Zeit vergeht..."3 y demuestra en Kontakte el continuo físico entre frecuencias sonoras y rítmicas, ${ }^{4}$ noción que el estadounidense enuncia desde 1930 en $\mathrm{New}$

3. Karlheinz Stockhausen, Die Reihe, núm. 3, I957 (“Cómo pasa el tiempo...”, también en traducción al francés, "Comment passe le temps", Contrechamps, París, Éditions L'Age d'Homme, núm. 9, I988, pp. 26-65).

4. Vínculo físico entre ritmo y sonido del mismo orden que el espacio-tiempo einsteiniano. Julio Estrada, "Focusing on Freedom and Movement in Music: Methods of Transcription Inside 
Music Resources, apoya con la invención instrumental del Rhythmicon' y desarrolla mediante una obra creativa que resurge después de ańos de persecución política además de un ominoso ninguneo del que es obviamente parte el propio Stockhausen.

Algunos otros méritos de Stockhausen provienen de su audacia para reinterpretar ideas ajenas a partir de intuiciones propias, como los Klavierstücke —al inicio de su obra serial-, que continúan el impulso de Modes de valeurs et intensités de Messiaen (1908-1992) y avanzan con sorpresiva dialéctica hacia el indeterminismo de Cage (1912-1992) y su escuela, también alimentada por Cowell:

Primer compositor que introdujo el concepto de "elasticidad" en su cuarteto para cuerdas No. 3-Mosaic —, que otorga a los intérpretes la posibilidad de organizar un conjunto de secuencias aisladas. Utiliza para ello una notación que él denomina "elástica" para dejar una parte de iniciativa a los músicos manipulando dentro de la partitura ciertos compases ad libitum. Esta idea fue ampliamente desarrollada más tarde por Cage, quien introduce la noción de componer como "proceso" — probablemente influido por Joyce. ${ }^{6}$

En concordancia con la apertura característica de la posguerra alemana, Stockhausen se conecta con la escuela experimental estadounidense desde dos perspectivas: la extravagancia contenida en Kurzwellen (1968), por arrancar de la proposición de Cage de emplear aparatos de radio como instrumentos del indeterminismo, y la pendiente al orientalismo, que amplifica a su vez la formación inicial con Messiaen, cuyo interés por los ritmos hindúes lo hace paradójicamente coincidir de nuevo con Cage. Las frecuentes versiones a posteriori que hace del indeterminismo descubren la mente del estratega musical para integrar una noción propia de azar, cuyo placentero aire conservador se posiciona entre el maestro francés y el sedicioso estadounidense, como ocurre en Momente (1962-1964), para pequeña orquesta, voz femenina y grupo vocal. De esa voz femenina solista emana un duelo inusual, acaso el germen doloroso y

a Continuum of Rhythm and Sound", Brandon Derfler (trad.), Perspectives of New Music, vol. 40, núm. I, invierno de 2002, pp. 70-9I.

5. Instrumento que Cowell encarga a Theremin para poder producir con él bajas frecuencias.

6. También alimentada por Cowell, como apunta en su último artículo Velia Nieto, "La forma abierta en la música del siglo xx", Anales del Instituto de Investigaciones Estéticas, México-Universidad Nacional Autónoma de México-Instituto de Investigaciones Estéticas, vol. xxx, núm. 92, primavera de 2008, p. 193. 
mudo que refiere a la eliminación en I94I de una madre depresiva, cruel sentencia del régimen nazi, tema que aborda mucho más tarde en la ópera Donnerstag aus Licht (1978-1980).

En los años previos a 1968, su biografía hecha de rupturas coincide con la gran mayoría de la música del siglo xx al enmascarar el sentimiento de pérdida y optar por ensayos entre abstractos y simbólicos, como el que denomina proceso de composición y plantea en Plus Minus (1963), o mejor aún en Prozession (1967), obra facturada con pequeños y significativos cálculos de la actividad instrumental con que el autor transforma citas aleatorias de sus propias partituras, autorretrato de un devenir histórico de dos décadas consagradas a una modernidad contingente.

Durante el crítico 1968, otro camino reconduce a Stockausen a la escuela de Cowell a través del contacto con la obra de los estadounidenses La Monte Young —alumno del alemán en Darmstadt_ y Pauline Oliveros, precursores de la creación musical a partir de sencillas instrucciones para el ejecutante que condujeron a la noción de partitura verbal, modelo que adopta Aus den sieben Tagen - "Al cabo de los siete días"-, serie de poemas escritos en una semana al borde, cuando se abraza a la tabla de salvación que le brinda la teosofía de Sri Aurobindo (I872-1950), ${ }^{7}$ autor de El hombre y la supermente, que lo aproxima en cierto modo a la relación psíquica y filosófica sostenida al final del siglo XIX por Nietzsche y Wagner:

El hombre es un ser en transición, no es el final. Porque en él y más allá de Él ascienden los radiantes grados por los que se trepa hacia la divinidad del superhombre. Los escalones que conducen del hombre al superhombre son el próximo acercamiento a la realización de la evolución en la tierra. Ahí es donde descansa nuestro destino. [...] La aparición del superhombre en el mundo humano será el cumplimiento de esta promesa brillante y distante. La diferencia entre el hombre y el superhombre será la diferencia entre mente y conocimiento. ${ }^{8}$

Adulto adolescente, contestatario y quimérico, símbolo de la década de 1960, Stockhausen justifica con Aurobindo una afirmación que parte en dos su obra y

7. Autor, entre otras obras, de Aforismos y Ojeadas y pensamientos, El ciclo humano, El secreto del Veda y La sintesis del yoga.

8. Traducción de Raúl Racedo: http://www.cainonline.com.ar/masnoticias/masnoticias.htm, enero de 2009. 
su persona: "He sońado varias veces que vengo de Sirius y que ahí fui entrenado como músico; esto fue algo casi obsesivo durante tres, cuatro años, y comencé a reunir información y a componer música electrónica que fue llamada Sirius" (1977). ${ }^{9}$ Es difícil disociar psicolingüísticamente al Sirius que adopta como origen de la idea del ario — arius —, tanto como el lapsus o extremo desvarío que lo lleva más de una década después a emitir una errática declaración en $200 \mathrm{I}$ sobre la destrucción de las Torres Gemelas de Nueva York:

Bien, lo ocurrido es, por supuesto la más grande obra de arte jamás hecha. El hecho que los espíritus han realizado con un único acto es algo con lo que nunca podremos sońar en música. Esa gente practicó diez años duramente, fanáticamente para un concierto. Y entonces murieron. Y eso es la más grande obra de arte que existe en todo el cosmos. [...] Yo no puedo realizar eso. Comparado con eso, no somos nada, como compositores. ${ }^{\text {IO }}$

El tono arbitrario y el desquiciamiento salpimentados por un carácter narcisista no le impiden ser un imán definitivo de la generación que le sigue, donde se sitúan Cornelius Cardew (1936-I98I) — cercano asistente y crítico opositor más tarde- Jean-Claude Eloy (1938) y yo mismo, en los cursos de composición de Colonia (1968-1969) y Darmstadt (1972), ${ }^{\mathrm{II}}$ durante un periodo en que, no obstante su esoterismo, mantuvo la claridad característica propia de las contribuciones que hace a la creación musical. Véase, de esa época, el orden de Stimmung (1968), ritual de un grupo vocal donde el método de canto difónico mongol se aplica en una escritura que revela el control definitivo de la nueva directriz, ${ }^{\mathrm{I} 2} \mathrm{o}$ Mantra, que renueva sus propios procesos de escritura serial.

Quizá el último gran creador que continúa la vieja tradición de un arte musical alemán asociado más que a otros a Wagner, Stockhausen, con sus

9. Paul McEnery, en http://archive.salon.com/people/bc/200I/oI/16/stockhausen/index.html Io. Karlheinz Stockhausen, MusikTexte, Colonia, 91, 2002, pp. 75-76.

I I. Antes lo fue la mexicana Luz Estela Santos, quien trabajó algunos años en la Radio de Colonia como su asistente y abandonó la composición pocos años después. El registro obliga a excluir a un tercero de cuyo nombre no quiero acordarme, penosamente expulsado del Conservatorio de Colonia en I 968 por el propio Stockhausen cuando resultó evidente que pretendió presentar en clase, como si fuera propio, mi análisis del Klavierstücke XI (1956), donde demostré la relación que mantenía el ritmo de dicha obra con la serie de Fibonacci.

I 2. Julio Estrada, "Stimmung, de Stockhausen”, Revista de la Universidad, vol. xxviI, núm. I I, julio de I973, pp. 45-48. 
abundantes aportes, alcanza una belleza nueva cuyo último periodo se sella con el predominio del pensamiento mágico. Sus últimas palabras, que parecen preparadas con singular antelación, nacen de un mismo credo y una misma ostentación que lo llevan a decir, a temprana hora del 5 de diciembre de 2007 — justo el aniversario de la muerte de Mozart—: "Hoy va a suceder algo extraordinario: acabo de aprender una nueva forma de respirar".

La frase sintetiza el tono esotérico de los últimos 40 años de vida que rompieron de súbito con la excesiva rigidez de su música serial integral, tendencia hoy representada, sólo simbólicamente, por un tardío sobreviviente de la posguerra musical europea, Pierre Boulez, cuyo ejemplo deslumbra a nuevas generaciones que prosiguen en el camino de la extinción. Stockhausen escapa del terco pasado con original gracia, aunque no del tono absolutista que le imprimió a él y a su obra artística un modernismo implacable capaz de mantener la continuidad del atrevimiento propio del Stravinski del Sacré o del trance expresado en la divisa picassiana: "no busco, sino encuentro". \$s 